\section{Muerte encefálica aparente tras sobredosis de baclofén}

\author{
Apparent brain death after a baclophen \\ overdose
}

\section{Sr. Director:}

El baclofén es un análogo lipofílico del ácido gammaaminobutírico, un neurotransmisor inhibidor presente en el sistema nervioso central ${ }^{1}$. Presentamos un caso de sobredosis de baclofén por intento autolítico, que se manifestó como coma profundo compatible con muerte encefálica.

Se avisó a los equipos de urgencias extrahospitalarias desde un domicilio, donde encontraron a un paciente de 18 años arreactivo en situación de gasping, por lo que de forma inmediata y sin precisar ninguna sedorrelajación se lo intubó y conectó a ventilación mecánica. A su llegada a urgencias, el paciente estaba en situación de coma profundo, con 3 puntos en la escala de coma de Glasgow, apirético, su presión arterial era de $120 / 60 \mathrm{mmHg}$, el pulso de 92 latidos/min y la saturación del pulsioxímetro del $100 \%$. La exploración física mostró flacidez y arreflexia generalizada, con pupilas medias y arreactivas. No se observó reflejo corneal ni oculocefálico. La respuesta a estímulos tusígenos y nauseosos era nula.

En la analítica destacaba un valor de CPK de $20.000 \mathrm{U} / \mathrm{l}$ y el perfil urinario toxicológico era negativo. Se efectuó de forma urgente una TAC craneal que se informó como normal. Se trasladó a la unidad de cuidados intensivos con el diagnóstico inicial de coma agudo y rabdomiolisis. Se inició fluidoterapia enérgica con alcalinización urinaria y se precisó, además, soporte vasoactivo para mantenimiento de cifras tensionales. Un electroencefalograma mostró enlentecimiento generalizado sin reactividad a la estimulación. En las $12 \mathrm{~h}$ siguientes, el paciente recuperó progresivamente el tono muscular y reaparecieron los reflejos tusígeno y corneal; $48 \mathrm{~h}$ más tarde el paciente obedecía órdenes sencillas. Se mantuvo apirético, los vasoactivos pudieron retirarse y se extubó al paciente, que estaba indemne a nivel neurológico, salvo por la presencia de una leve disartria. El paciente relató que había ingerido con fines suicidas 60 tabletas de baclofén (beflón [ $5 \mathrm{mg} /$ tableta]), medicación que tomaba un amigo suyo afectado de espasticidad por parálisis cerebral. Pasó a planta al cuarto día del ingreso. Nuestro paciente presentó una recuperación funcional ad integrum a pesar de la abolición total de reflejos del tronco encefálico. Esta reversibilidad total de la clínica orientó a un origen tóxico como causa fundamental, lo que fue después corroborado por el paciente. La sobredosis por baclofén está descrita tras la administración oral o intratecal de este ${ }^{2,3}$. El baclofén tiene una buena absorción intestinal, su eliminación es casi exclusivamente renal y su vida media oscila entre $2-6 \mathrm{~h}^{4}$. Todas las manifestaciones clínicas son consecuencia de la depresión central y de la relajación muscular extrema mediadas por la estimulación de los receptores del ácido gamma-aminobutírico $B$ a nivel espinal, del tronco y el hipocampo. Coma, arreflexia y apnea son los principales efectos, a los que pueden añadirse hipotensión, bradicardia y alteraciones de la termorregulación. El diagnóstico es clínico, ya que no está disponible la monitorización de los niveles de este fármaco en todos los centros. El tratamiento es fundamentalmente de soporte, pues no hay ningún antídoto disponible. Se ha afirmado que el flumazenil, un antagonista de las benzodiacepinas, podría neutralizar los efectos del baclofén a nivel central, pero la evidencia científica es contradicto$\mathrm{ria}^{5}$. Como conclusión, la sobredosis de baclofén puede originar un coma profundo que simule una situación de muerte encefálica.

\section{Bibliografía}

1. Grenier B, Mesli A, Cales J, Castel JP, Maurette P. Hyperthermie grave liée à un sevrage brutal de baclofène administré de façon continue par voie intrathécale. Ann Fr Anesth Réanim. 1996;15: 659-662.

2. Lew SM, Psaty EL, Abbot R. An unusual case of overdose after baclofen pump implantation: Case report. Neurosurgery. 2005;56:E624.

3. Chong CF, Wang TL. An unusual presentation of baclofen overdose. Emerg Med J. 2005;22:673-4.

4. Wall G, Wasiak A, Hicklin GA. An initially unsuspected case of baclofen overdose. Am J Crit Care. 2006;15:611-13.

5. Byrnes SM, Watson GW, Hardy PA. Flumazenil: An unreliable antagonist in baclofen overdose. Anaesthesia. 1996;51:481-2.

R. Salas De Zayas*, F. San José Pacheco, C. Dolera Moreno y L. Zoila Peiró

Unidad de Cuidados Intensivos, Hospital Universitario S. Joan, Alicante, España

*Autor para correspondencia.

E-mail address: auroragorda@hotmail.com

(R. Salas De Zayas). 